\title{
A Mediterranean lifestyle is associated with favourable cardiometabolic markers in people with non-dialysis dependent chronic kidney disease
}

\author{
Katelyn Bowden $^{1}$ (D), Nicholas A Gray ${ }^{1,2,3}$ (D) Elizabeth Swanepoel ${ }^{1}$ and Hattie H Wright ${ }^{1,3 *}$ (D) \\ ${ }^{1}$ School of Health and Behavioural Sciences, University of the Sunshine Coast, Maroochydore, Queensland, Australia \\ ${ }^{2}$ Department of Nephrology, Sunshine Coast Hospital and Health Service, Birtinya, Queensland, Australia \\ ${ }^{3}$ Sunshine Coast Health Institute, Birtinya, Queensland, Australia
}

(Received 4 January 2021 - Final revision received 25 April 2021 - Accepted 30 April 2021)

Journal of Nutritional Science (2021), vol. 10, e42, page 1 of 8

doi:10.1017/jns.2021.33

Abstract

Adherence to a Mediterranean lifestyle may be a useful primary and secondary prevention strategy for chronic kidney disease (CKD). This cross-sectional study aimed to explore adherence to a Mediterranean lifestyle and its association with cardiometabolic markers and kidney function in 99 people aged $73 \cdot 2 \pm 10 \cdot 5$ years with non-dialysis dependant CKD (stages 3-5) at a single Australian centre. Adherence was assessed using an a priori index, the Mediterranean Lifestyle (MEDLIFE) index. Cardiometabolic markers (total cholesterol, LDL-cholesterol, HbA1c and random blood glucose) and kidney function (estimated GFR) were sourced from medical records and blood pressure measured upon recruitment. Overall, adherence to a Mediterranean lifestyle was moderate to low with an average MEDLIFE index score of $11 \cdot 33 \pm 3 \cdot 31$. Adherence to a Mediterranean lifestyle was associated with employment $(r 0 \cdot 30, P=0 \cdot 004)$. Mediterranean dietary habits were associated with cardiometabolic markers, such as limiting sugar in beverages was associated with lower diastolic blood pressure $(r 0 \cdot 32, P=0 \cdot 002)$, eating in moderation with favourable random blood glucose $(r 0 \cdot 21, P=0 \cdot 043)$, having more than two snack foodsper week with $\mathrm{HbA1c}(r 0 \cdot 29, P=0 \cdot 037)$ and LDL-cholesterol $(r 0 \cdot 41, P=0 \cdot 002)$. Interestingly, eating in company was associated with a lower frequency of depression $\left(\chi^{2} 5 \cdot 975, P=0 \cdot 015\right)$. To conclude, Mediterranean dietary habits were favourably associated with cardiometabolic markers and management of some comorbidities in this group of people with non-dialysis dependent CKD.

Key words: Dietary components: Dietary habits: Kidney disease: Lifestyle behaviour: Mediterranean diet

\section{Introduction}

Chronic kidney disease (CKD) affects $9.1 \%$ of the population worldwide, placing substantial burden on healthcare systems $^{(1,2)}$. The development and rapid progression of kidney dysfunction is associated with sub-optimal dietary intake ${ }^{(3)}$. Not only is low diet quality detrimental to CKD, it can also result in poor management of underlying comorbidities like cardiovascular disease, diabetes mellitus and hypertension which can further progress $\mathrm{CKD}^{(3,4)}$. For these reasons, there is potential for healthful dietary patterns, like the Mediterranean diet, to aid in the prevention and management of $\mathrm{CKD}^{(5)}$.

Emerging evidence links a Mediterranean diet with improved cardiometabolic health, glycaemic control and reduced incidence of $\mathrm{CKD}^{(5-8)}$. The Mediterranean diet is based on high intake of fruits, vegetables, whole-grain bread and cereals, olive oil, legumes, nuts and seeds; moderate intake of dairy products, egg, seafood, poultry and wine; low intake of red meat and discretionary foods ${ }^{(9)}$. In a multi-centre trial, a Mediterranean diet supplemented with extra-virgin olive oil or nuts was associated with a $31 \%$ lower incidence of major cardiovascular events in people at high cardiovascular risk $^{(8)}$. Moreover, the Mediterranean diet has been associated with lower blood pressure, low-density lipoprotein and higher estimated glomerular filtration rate (eGFR) in people with $\mathrm{CKD}^{(10)}$. Likewise, adherence to a Mediterranean diet was associated with reduced levels of HbA1c, plasma glucose and insulin in adults with and without type 2 diabetes mellitus ${ }^{(11,12)}$. Lastly, a recent prospective cohort study among

* Corresponding author: Hattie H. Wright, email hwright@usc.edu.au 
CKD patients found that those with highest adherence to a Mediterranean diet had a lower adjusted risk for CKD progression $^{(13)}$. Taken together, a Mediterranean diet seems to be a prudent diet for people at risk of or with CKD, due to its impact on comorbidities, which may contribute to the development or progression of CKD.

The protective effects of a Mediterranean diet may not only be due to the intake of nutrients and foods but also include non-nutrient factors such as psychological, social and physical factors that represent a Mediterranean lifestyle ${ }^{(14,15)}$. These factors have been shown to modulate comorbidities associated with CKD and to a lesser extent, CKD and its progres$\operatorname{sion}^{(16,17)}$. Physical activity is well documented to decrease body weight, blood pressure, low-density lipoprotein and total cholesterol levels ${ }^{(15,18-21)}$. Moreover, sedentary behaviour and reduced physical activity are associated with an increased risk of $\mathrm{CKD}$, as well as increased mortality and decline in renal function in $\mathrm{CKD}$ populations ${ }^{(15,19)}$. Socialisation has been identified to be inversely associated with the presence of hypertension $^{(17)}$ and depression ${ }^{(22)}$. Lastly, conviviality has been associated with healthy weight, improved eating habits and dietary choices ${ }^{(23)}$. Taken together, it appears the benefits of a Mediterranean lifestyle are not exclusive to dietary intake; thus, further consideration to its role in the health outcomes and progression of kidney disease in people with non-dialysis dependent CKD is warranted.

The aim of the present study was to investigate the adherence to a Mediterranean lifestyle and its association with cardiometabolic markers and kidney function in people with non-dialysis dependent CKD from a non-Mediterranean country.

\section{Methods}

\section{Study design and setting}

This cross-sectional observational study was conducted at the Nephrology department of the Sunshine Coast Hospital and Health Service, Queensland, Australia. People with nondialysis dependent CKD stages 3 to 5 (eGFR $\leq 60 \mathrm{ml} / \mathrm{min}$ / $1.73 \mathrm{~m}^{2}$ ) were recruited via convenience sampling. The CKD stage was determined according to the National Kidney Foundation clinical practice guidelines ${ }^{(24)}$. The primary outcome was adherence to a Mediterranean lifestyle and secondary outcomes were kidney function and cardiometabolic health. Dependent variables were kidney function (eGFR) and cardiometabolic markers (total cholesterol, LDLcholesterol, HbA1c, random blood glucose and blood pressure). Independent variables included Mediterranean lifestyle adherence, socioeconomic status, the presence of comorbidities, age, weight and body mass index (BMI). Exclusion criteria included kidney transplant recipients, people receiving dialysis, non-English-speaking individuals, cognitive impairment, pregnancy and current enrolment in another research project. Nil reimbursement or incentives were provided. Participants provided written informed consent prior to inclusion to the study. Ethical approval was obtained from the Prince Charles Hospital Human Research Ethics Committee (HREC/17/QPCH/370) and the University of the Sunshine Coast Human Research Ethics committee (S181179).

\section{Measurements}

Height, weight and brachial blood pressure were measured by trained clinical nurses using standard protocols ${ }^{(25,26)}$ during a routine visit at the Nephrology department. BMI was calculated from height and weight measurements and categorised according to the World Health Organisation Criteria (Healthy: BMI $\geq 18.5$ to $<25 \mathrm{~kg} / \mathrm{m}^{2}$; Overweight: BMI $\geq 25$ to $<30 \mathrm{~kg} / \mathrm{m}^{2}$; Obese: BMI $\left.\geq 30 \mathrm{~kg} / \mathrm{m}^{2}\right)^{(27)}$. The most recent biochemical parameters (taken within the last 6-months), the number of diagnosed comorbidities (including diabetes, cardiovascular disease, hypertension and depression) and medication use were recorded from medical charts.

\section{Questionnaire}

Socio-demographic information, source of nutrition information and Mediterranean lifestyle habits were assessed using a self-administered paper-based survey.

Socio-demographic information. Socio-demographic data included age, sex, country of birth, employment, educational attainment, marital status, previous dietetic input and postcode. Employment status and level of education were surrogates for socioeconomic status.

Mediterranean lifestyle habits. The Mediterranean lifestyle (MEDLIFE) index ${ }^{(28)}$ was used to assess adherence to a Mediterranean lifestyle, including diet, physical activity patterns and social interaction. The MEDLIFE index has been validated in a middle-aged Spanish working-class cohort and showed significant association with the Alternate Mediterranean Diet Index and the Mediterranean Diet Adherence Screener ${ }^{(28)}$. The index consists of 28-items which are divided into three blocks, namely (1) food consumption (fifteen items), (2) traditional Mediterranean dietary habits (seven items) and (3) physical activity, rest, social habits and conviviality (six items). In block one, participants self-reported the average number of serves of specific foods and beverages using visual guides on portion sizes which was provided by the research team. Block two and three indicated adherence to Mediterranean dietary and lifestyle habits, respectively. Each item was scored one point if the guideline was met or zero if the guideline was not met, resulting in a total score out of 28. The higher the score, the greater adherence to a Mediterranean lifestyle is.

Sample size estimation. A total sample size of 102 was calculated using G-power ${ }^{(29)}$ with a medium effect size $(\delta 0 \cdot 50)$, $80 \%$ power and significance set at $P<0.05$ to identify differences between two independent groups. A total of 111 participants were recruited between July and September 2020, of which 12 participants did not return their surveys, resulting in a final sample size of 99 ( $89 \%$ response rate).

\section{Statistical analysis}

Data analysis was performed using IBM SPSS statistical software package version 24 (SPSS, Inc., Chicago, IL, USA) and 
Table 1. Participant demographics and comorbidities ( $n$ 99)

\begin{tabular}{|c|c|c|c|c|c|c|c|c|c|c|}
\hline \multirow[b]{2}{*}{ Characteristics } & \multicolumn{2}{|c|}{ Total group ( $n$ 99) } & \multicolumn{2}{|c|}{$\begin{array}{l}\text { MEDLIFE index score } \\
\leq \text { Median }(n 50)\end{array}$} & \multicolumn{2}{|c|}{$\begin{array}{l}\text { MEDLIFE index score } \\
>\text { Median }(n 47)\end{array}$} & \multicolumn{2}{|c|}{ CKD stage 3 ( $n$ 47) } & \multicolumn{2}{|c|}{$\begin{array}{l}\text { CKD stages } 4 \text { to } 5 \\
(n 52)\end{array}$} \\
\hline & $\begin{array}{l}\text { Mean/ } \\
\text { Median }\end{array}$ & sD/IQR & $\begin{array}{l}\text { Mean/ } \\
\text { Median }\end{array}$ & SD/IQR & $\begin{array}{l}\text { Mean/ } \\
\text { Median }\end{array}$ & SD/IQR & $\begin{array}{l}\text { Mean/ } \\
\text { Median }\end{array}$ & sD/IQR & $\begin{array}{l}\text { Mean/ } \\
\text { Median }\end{array}$ & SD/IQR \\
\hline Age (years) & $73 \cdot 2$ & $10 \cdot 5$ & $72 \cdot 1$ & $10 \cdot 4$ & $74 \cdot 1$ & $10 \cdot 7$ & $72 \cdot 7$ & $10 \cdot 2$ & $74 \cdot 0$ & $10 \cdot 8$ \\
\hline Body weight (kg) & $88 \cdot 2$ & $18 \cdot 8$ & $88 \cdot 7$ & $16 \cdot 8$ & $88 \cdot 0$ & $21 \cdot 1$ & $88 \cdot 3$ & $20 \cdot 6$ & $88 \cdot 1$ & $17 \cdot 4$ \\
\hline Body mass index ${ }^{a}\left(\mathrm{~kg} / \mathrm{m}^{2}\right)$ & $30 \cdot 0$ & $\begin{array}{l}26 \cdot 2 \\
34 \cdot 4\end{array}$ & $30 \cdot 7$ & $\begin{array}{l}26 \cdot 1 \\
35 \cdot 0\end{array}$ & $28 \cdot 3$ & $\begin{array}{l}26 \cdot 2 \\
33 \cdot 1\end{array}$ & $29 \cdot 0$ & $\begin{array}{l}26 \cdot 1 \\
34 \cdot 7\end{array}$ & $30 \cdot 6$ & $\begin{array}{l}26 \cdot 2 \\
34 \cdot 3\end{array}$ \\
\hline $\begin{array}{l}\text { Systolic blood pressure } \\
\quad(\mathrm{mmHg})\end{array}$ & 140 & $20 \cdot 0$ & 141 & $19 \cdot 2$ & 140 & $20 \cdot 7$ & $133^{*}$ & $19 \cdot 6$ & 146 & 18 \\
\hline $\begin{array}{l}\text { Diastolic blood pressure } \\
\quad(\mathrm{mmHg})\end{array}$ & 76 & $8 \cdot 5$ & 77 & $7 \cdot 2$ & 75 & $9 \cdot 5$ & 75 & $9 \cdot 3$ & $6 \cdot 4$ & $7 \cdot 7$ \\
\hline \multirow[t]{2}{*}{ eGFR ${ }^{b}\left(\mathrm{ml} / \mathrm{min} / 1.73 \mathrm{~m}^{2}\right)$} & 30 & $13 \cdot 1$ & 29 & $13 \cdot 0$ & 31 & $3 \cdot 7$ & $41 \cdot 6^{\star}$ & $8 \cdot 9$ & $20 \cdot 1$ & $6 \cdot 1$ \\
\hline & $N$ & $\%$ & $N$ & $\%$ & $N$ & $\%$ & $N$ & $\%$ & $N$ & $\%$ \\
\hline Married & 50 & 50 & 26 & 52 & 24 & 51 & 20 & 43 & 30 & 58 \\
\hline Male & 64 & 64 & 35 & 70 & 28 & 60 & 27 & 59 & 36 & 69 \\
\hline Employed $^{c}$ & 13 & 13 & 4 & 8 & 9 & 19 & 5 & 11 & 7 & 13 \\
\hline \multicolumn{11}{|l|}{ Education } \\
\hline No formal & 16 & 16 & 7 & 14 & 9 & 19 & 10 & 22 & 6 & 12 \\
\hline Secondary & 44 & 44 & 21 & 42 & 22 & 47 & 20 & 43 & 24 & 46 \\
\hline Tertiary or vocational & 39 & 40 & 22 & 44 & 16 & 34 & 16 & 35 & 22 & 42 \\
\hline \multicolumn{11}{|l|}{ Presence of comorbidities ${ }^{d}$} \\
\hline Hypertension & 64 & 65 & 31 & 62 & 32 & 68 & 24 & $52^{\#}$ & 40 & 77 \\
\hline CVD & 49 & 50 & 28 & 56 & 20 & 43 & 21 & 46 & 28 & 54 \\
\hline Diabetes & 51 & 52 & 24 & 48 & 27 & 57 & 20 & 43 & 31 & 60 \\
\hline Cancer & 20 & 20 & 8 & 16 & 11 & 23 & 5 & $11^{\$}$ & 15 & 29 \\
\hline Depression & 19 & 19 & 10 & 20 & 8 & 17 & 12 & 26 & 7 & 13 \\
\hline
\end{tabular}

Note. Data presented as mean and standard deviation (SD), median and interquartile range (IQR, 25th; 75th percentile), or frequency and percentage of the total group.

MEDLIFE, Mediterranean lifestyle; CKD, chronic kidney disease; eGFR, estimated glomerular filtration rate; CVD, cardiovascular disease.

a Data missing for thirteen participants.

${ }^{\mathrm{b}}$ Data missing for one participant.

${ }^{\mathrm{c}}$ Includes full-time, part-time and casual employment.

dParticipants presented with multiple comorbidities; values do not add up to 100 .

* Significant difference between CKD stage 3 compared with stages 4 and $5, P<0.01$.

${ }^{\#} \chi^{2} 6.599, P=0.01$.

$\$ \chi^{2} 4.856, P=0.028$.

significance set at $P<0 \cdot 05$. Descriptive statistics are presented as mean and standard deviation (SD) for parametric variables or median and interquartile range (IQR) for non-parametric variables. Categorical data are presented as frequencies and percentage of the total group. Data were stratified into dichotomous groups according to the median MEDLIFE index score of the cohort (cut-off: $\leq 11 v .>11$ ). Additionally, participants were stratified based on kidney function, early (stages $3 \mathrm{a}$ and $3 \mathrm{~b}$ ) or advanced CKD (stages 4 and 5) to explore differences in socio-demographic and cardiometabolic markers. Differences between groups were determined with independent $T$-tests for parametric variables, Mann-Whitney $U$ tests for nonparametric variables and $\chi^{2}$ test for categorical variables. Associations between independent and dependent variables were explored using $\chi^{2}$ test or Pearson correlations, adjusting for age, gender and weight. Adjusted $\mathrm{R}$-values are reported unless otherwise indicated.

\section{Results}

\section{Participant characteristics and cardiometabolic markers}

Participant demographics and comorbidities are summarised in Table 1 for the total group, as well as between groups based on the MEDLIFE index score and kidney function.
Participants were mostly male, older than 70 years of age, unemployed and the majority obtained either a secondary or tertiary education. Overall, $32 \cdot 6 \%$ were classified as overweight and $50.0 \%$ were obese. Most participants presented with two or more comorbidities, with only $7 \cdot 3 \%$ of participants presenting with no comorbidity and $25.0 \%$ presenting with one comorbidity. Significant differences were found between systolic blood pressure and a diagnosis of hypertension and/or cancer between those with early CKD compared with advanced CKD.

Table 2 shows biochemistry, MEDLIFE index score and cardiometabolic markers for the group. No significant differences were found for cardiometabolic markers or kidney function between groups according to the median MEDLIFE index score. Significant differences were found in creatinine, potassium, phosphate and triacylglycerols between those with early CKD compared with advanced CKD.

The most common source of nutrition information was a dietitian $(30.3 \%)$, doctor $(29.3 \%)$, friends or family $(29 \cdot 3$ $\%)$ and the internet or online resources $(21 \cdot 2 \%)$.

\section{Mediterranean lifestyle habits}

Two participants completed less than $70 \%$ of the MEDLIFE index and were omitted from data analysis. The average 
Table 2. Participant biochemistry, cardiometabolic markers and Mediterranean lifestyle index ( $n$ 99)

\begin{tabular}{|c|c|c|c|c|c|c|c|c|c|c|}
\hline \multirow[b]{2}{*}{ Measurements and characteristics } & \multicolumn{2}{|c|}{$\begin{array}{l}\text { Total group } \\
(n 99)\end{array}$} & \multicolumn{2}{|c|}{$\begin{array}{l}\text { MEDLIFE index } \\
\text { score } \leq \text { Median } \\
(n 50)\end{array}$} & \multicolumn{2}{|c|}{$\begin{array}{l}\text { MEDLIFE index } \\
\text { score > Median } \\
(n 47)\end{array}$} & \multicolumn{2}{|c|}{$\begin{array}{l}\text { CKD stage } 3 \\
(n 47)\end{array}$} & \multicolumn{2}{|c|}{$\begin{array}{l}\text { CKD stages } 4 \text { to } \\
5(n 52)\end{array}$} \\
\hline & Mean & SD & Mean & SD & Mean & SD & Mean & SD & Mean & SD \\
\hline MEDLIFE Index score & $11 \cdot 3$ & 3.3 & $8 \cdot 8$ & 1.9 & $14 \cdot 0$ & $2 \cdot 1$ & $11 \cdot 8$ & 2.9 & $10 \cdot 8$ & 3.5 \\
\hline Creatinine $^{a}(u m o l / l)$ & 203 & $89 \cdot 3$ & 210 & $88 \cdot 3$ & 198 & $91 \cdot 7$ & $134^{*}$ & $21 \cdot 3$ & 265 & $80 \cdot 7$ \\
\hline Albumin $^{b}(g / l)$ & 40 & $3 \cdot 7$ & 40 & $3 \cdot 7$ & 40 & $3 \cdot 7$ & 40 & $3 \cdot 7$ & 40 & 3.7 \\
\hline Potassium $^{\mathrm{a}}$ (mmol/l) & 4.5 & 0.5 & $4 \cdot 6$ & 0.5 & 4.5 & 0.5 & $4 \cdot 4^{\star}$ & 0.4 & $4 \cdot 7$ & 0.5 \\
\hline Phosphate $^{\mathrm{a}}(\mathrm{mmol} / \mathrm{l})$ & $1 \cdot 2$ & 0.2 & $1 \cdot 2$ & 0.2 & $1 \cdot 2$ & 0.3 & $1 \cdot 1^{*}$ & $0 \cdot 2$ & $1 \cdot 3$ & 0.2 \\
\hline Random blood glucose ${ }^{b}(\mathrm{mmol} / \mathrm{l})$ & $7 \cdot 1$ & $3 \cdot 0$ & $7 \cdot 3$ & $3 \cdot 2$ & $6 \cdot 9$ & $2 \cdot 8$ & $7 \cdot 0$ & $2 \cdot 8$ & $7 \cdot 1$ & $3 \cdot 1$ \\
\hline $\mathrm{HbA} 1 \mathrm{c}^{\mathrm{c}}(\%)$ & 7.5 & 1.9 & $7 \cdot 5$ & $2 \cdot 2$ & $7 \cdot 5$ & 1.5 & $7 \cdot 3$ & $1 \cdot 8$ & $7 \cdot 6$ & $2 \cdot 0$ \\
\hline Total cholesterol ${ }^{\mathrm{c}}(\mathrm{mmol} / \mathrm{l})$ & 4.4 & $1 \cdot 2$ & $4 \cdot 2$ & $1 \cdot 1$ & 4.5 & $1 \cdot 3$ & $4 \cdot 3$ & $1 \cdot 2$ & 4.5 & $1 \cdot 3$ \\
\hline HDL-cholesterol $^{\mathrm{d}}(\mathrm{mmol} / \mathrm{l})$ & $1 \cdot 1$ & 0.3 & $1 \cdot 1$ & 0.3 & $1 \cdot 1$ & 0.3 & $1 \cdot 2$ & 0.3 & 1.0 & 0.3 \\
\hline LDL-cholesterol $^{\mathrm{d}}(\mathrm{mmol} / \mathrm{l})$ & $2 \cdot 1$ & 0.9 & $2 \cdot 1$ & 0.9 & $2 \cdot 1$ & 0.8 & $2 \cdot 2$ & 0.9 & $2 \cdot 1$ & 0.9 \\
\hline Triacylglycerols $^{\mathrm{e}}(\mathrm{mmol} / \mathrm{l})$ & 1.9 & 0.9 & 1.9 & 0.8 & 1.9 & $1 \cdot 0$ & $1 \cdot 7^{\star *}$ & 0.7 & $2 \cdot 1$ & $1 \cdot 1$ \\
\hline
\end{tabular}

Note. Data presented as mean and standard deviation (SD).

MEDLIFE, Mediterranean lifestyle; CKD, chronic kidney disease; HbA1c, glycated haemoglobin A1C; HDL, high-density lipoprotein; LDL, low-density lipoprotein.

${ }^{\text {a }}$ Data missing for one participant.

${ }^{b}$ Data missing for three participants.

${ }^{c}$ Data missing for seven participants, nil readings within 6 months.

${ }^{\mathrm{d}}$ Data missing for forty participants, nil readings within 6 months.

${ }^{\text {e}}$ Data missing for thirteen participants, nil readings within 6 months.

* Significant difference between CKD stage 3 compared with stages 4 and $5, P<0.01$.

** Significant difference between CKD stage 3 compared with stages 4 and $5, P<0.05$.

MEDLIFE index score for the total group was $11 \cdot 3 \pm 3 \cdot 3$ ( $n$ 97). Table 3 represents the average scores for each block, as well as individual items of the MEDLIFE index.

Considering the recommended cut-offs for Mediterranean food consumption, on average, the number of serves for vegetables was met and most participants used herbs and spices to flavour food. In contrast, the number of serves for pastries, red meat, processed meat and potatoes were in excess, while the number of serves for legumes, low-fat dairy, olive oil, nuts, fruit, fish and seafood were not met. The majority of participants met the criteria for Mediterranean dietary habits with the exception of drinking wine daily at mealtimes. Over half of the participants met criteria for most Mediterranean lifestyle habits, excluding television viewing, participation in team sports or physical activity and socialising with friends.

\section{Correlations}

Socio-demographics and Mediterranean lifestyle. The total MEDLIFE index score was associated with employment which remained significant after adjusting for age and gender ( $r$ 0.30, $P=0.004)$. An association between women and preference to consume fresh, minimally processed and seasonal produce $\left(\chi^{2} 6 \cdot 525, P=0 \cdot 011\right)$, as well as preference to eat in moderation and trying to choose small portions $\left(\chi^{2} 10 \cdot 371, P<0 \cdot 01\right)$ was found. There was an association between men and eating in company $\left(\chi^{2}\right.$ 6.047, $\left.P=0 \cdot 014\right)$. Previous dietetic input was associated with consumption of fresh, minimally processed and seasonal produce $\left(\chi^{2} 3 \cdot 670, P=0 \cdot 055\right)$.

Cardiometabolic markers, kidney function and Mediterranean lifestyle. Kidney function was negatively associated with systolic blood pressure which remained significant after adjusting for confounders $(r-0.32, P=0.002)$. Kidney function was associated with not receiving nutrition information from the internet or online sources $(r 0 \cdot 23, P=0 \cdot 026)$.

The total MEDLIFE index score was negatively associated with diastolic blood pressure but lost significance after adjusting for confounders $(r-0 \cdot 20, P=0 \cdot 058)$. Adherence to limiting sugar in beverages was associated with lower diastolic blood pressure before and after adjusting for confounders $(r 0 \cdot 32, P=0 \cdot 002)$.

Body weight was negatively associated with HDLcholesterol $(r-0 \cdot 40, P=0 \cdot 002)$. Not adhering to consumption of less than two servings of snack foods per week was associated with LDL-cholesterol after adjusting for confounders ( $0.41, P=0.002)$. An association was also found with total cholesterol, but significance was lost after adjusting for confounders $(r 0 \cdot 21, P=0 \cdot 054)$. Interestingly, preference of minimally processed and seasonal produce and preference to eat in moderation and choosing small portions was inversely associated with total cholesterol after adjusting for confounders $(r-0 \cdot 25, P=0 \cdot 019$; $r-0 \cdot 22, P=0 \cdot 04$, respectively).

Random plasma glucose was associated with non-adherence to eating in moderation and trying to choose small portions and

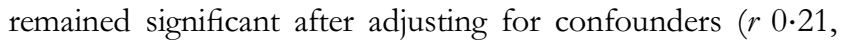
$P=0 \cdot 043)$. In addition, there was an association between participants presenting with diagnosed diabetes and nonadherence to preference to eat in moderation and trying to choose small portions $\left(\chi^{2} 4 \cdot 174, P=0 \cdot 041\right)$. Not adhering to consumption of less than two servings of snack foods per week was associated with $\mathrm{HbA1c}$ and remained significant after adjusting for confounders $(r 0 \cdot 29, P=0 \cdot 037)$.

Interestingly, eating in company was associated with a lower frequency of diagnosed depression $\left(\chi^{2} 5 \cdot 975, P=0 \cdot 015\right)$.

\section{Discussion}

The present study aimed to investigate adherence to a Mediterranean lifestyle and its association with 
Table 3. Adherence to a Mediterranean lifestyle, the MEDLIFE index raw scores ( $n$ 97)

\begin{tabular}{|c|c|c|c|c|c|c|}
\hline & & \multirow{2}{*}{ Criteria for 1 point $^{\mathrm{a}}$} & \multirow{2}{*}{$\frac{\text { Average serves }^{\mathrm{b}}}{\text { Mean }}$} & \multicolumn{3}{|c|}{$\begin{array}{l}\text { Participants who met } \\
\text { criteria }\end{array}$} \\
\hline & & & & SD & $N$ & $\%$ \\
\hline \multicolumn{7}{|c|}{ Block 1: Mediterranean food consumption } \\
\hline 1. Sweets & $\begin{array}{l}\text { Candy }(1 \mathrm{~s}=1 \text { unit or } 50 \mathrm{~g}) \text {, chocolates } \\
\quad(1 \mathrm{~s}=30 \mathrm{~g}) \text {, biscuits }(1 \mathrm{~s}=4-6 \text { units })\end{array}$ & $\leq 2 \mathrm{~s} /$ week & $6 \cdot 6$ & $6 \cdot 2$ & 26 & $26 \cdot 3$ \\
\hline 2. Red meat & $\begin{array}{l}\text { Beef, pork, kangaroo, lamb } \\
\quad(1 \mathrm{~s}=90-100 \mathrm{~g})\end{array}$ & $<2 \mathrm{~s} /$ week & $4 \cdot 0$ & $2 \cdot 7$ & 41 & 41.4 \\
\hline 3. Processed meat & $\begin{array}{l}\text { Ham/salami }(1 \mathrm{~s}=1 \text { slice or } 30 \mathrm{~g}) \\
\text { sausage, bacon }(1 \mathrm{~s}=50 \mathrm{~g} / 2 \text { rasher }) \\
\text { hamburger }(1 \mathrm{~s}=1 \text { patty }) \text {, liver } \\
(1 \mathrm{~s}=100-150 \mathrm{~g}), \text { pate }(1 \mathrm{~s}=25 \mathrm{~g})\end{array}$ & $\leq 1 \mathrm{~s} /$ week & $2 \cdot 9$ & $3 \cdot 1$ & 20 & $20 \cdot 2$ \\
\hline 4. Eggs & Eggs (1 egg) & $2-4$ s/week & 3.7 & $3 \cdot 1$ & 39 & 39.4 \\
\hline 5. Legumes & $\begin{array}{l}\text { Lentils, beans, peas, chickpeas } \\
\qquad(1 \mathrm{~s}=1 \text { cup or } 150 \mathrm{~g})\end{array}$ & $\geq 2 \mathrm{~s} /$ week & 0.9 & 1.4 & 22 & $22 \cdot 2$ \\
\hline 6. White meat & Poultry, rabbit $(1 \mathrm{~s}=100-150 \mathrm{~g})$ & 2 s/week & $2 \cdot 3$ & 1.4 & 21 & $21 \cdot 2$ \\
\hline 7. Fish/seafood & $\begin{array}{l}\text { White/oily fish }(1 \mathrm{~s}=100-150 \mathrm{~g}) \text {, canned } \\
\text { fish }(1 \mathrm{~s}=1 \text { can or } 50 \mathrm{~g}) \text {, seafood } \\
\quad(1 \mathrm{~s}=200 \mathrm{~g})\end{array}$ & $\geq 2 \mathrm{~s} /$ week & 1.4 & $1 \cdot 2$ & 35 & $35 \cdot 4$ \\
\hline 8. Potatoes & $\begin{array}{l}\text { Roast/boiled potatoes, French fries/hot } \\
\text { chips }(1 \mathrm{~s}=150-200 \mathrm{~g})\end{array}$ & $\leq 3 \mathrm{~s} /$ week & $4 \cdot 4$ & $2 \cdot 9$ & 40 & $40 \cdot 4$ \\
\hline 9. Low-fat dairy & $\begin{array}{l}\text { Skimmed dairy milk ( } 1 \mathrm{~s}=250 \mathrm{ml} \text { milk, } \\
\text { two small yoghurts or } 200 \mathrm{~g} \text { tub, } \\
1 \text { portion cheese) }\end{array}$ & $2 \mathrm{~s} / \mathrm{d}$ & $1 \cdot 0$ & $1 \cdot 2$ & 12 & $12 \cdot 1$ \\
\hline 10. Nuts and olives & $\begin{array}{l}\text { Walnuts, almonds, hazelnuts ( } 1 \mathrm{~s}=1 \\
\text { handful or } 30 \mathrm{~g} \text { ), olives ( } 1 \mathrm{~s}=10 \text { units) }\end{array}$ & $1-2 \mathrm{~s} / \mathrm{d}$ & 0.3 & $0 \cdot 8$ & 24 & $24 \cdot 2$ \\
\hline 11. Herbs, spices, garnish & Onion, garlic, herbs (parsley, oregano) & $\geq 1 \mathrm{~s} / \mathrm{d}$ & 0.6 & 0.8 & 54 & 54.5 \\
\hline 12. Fruit & $\begin{array}{l}\text { All fruit and fresh fruit-based juices } \\
\qquad(1 \mathrm{~s}=150-200 \mathrm{~g} \text { or } 125 \mathrm{ml} \text { juice })\end{array}$ & $3-6 s / d$ & $1 \cdot 6$ & $1 \cdot 3$ & 14 & $14 \cdot 1$ \\
\hline 13. Vegetables & $\begin{array}{l}\text { All vegetables except potatoes } \\
\qquad(1 \mathrm{~s}=150-200 \mathrm{~g})\end{array}$ & $\geq 2 \mathrm{~s} / \mathrm{d}$ & $2 \cdot 1$ & $1 \cdot 3$ & 62 & $62 \cdot 6$ \\
\hline 14. Olive oil & Olive oil $(1 \mathrm{~s}=1 \mathrm{tbsp})$ & $\geq 3 \mathrm{~s} / \mathrm{d}$ & 0.8 & 1.7 & 4 & 4.0 \\
\hline 15. Cereals & $\begin{array}{l}\text { White and whole-grain bread ( } 1 \mathrm{~s}=1 \\
\text { slice or } 40 \mathrm{~g}) \text {, cereals }(1 \mathrm{~s}=1 / 2 \text { cup } \\
\text { rice, pasta) or ( } 1 \mathrm{~s}=1 / 2 \text { cup or small } \\
\text { bowl of porridge, breakfast cereals) } \\
\text { and derivatives }\end{array}$ & $3-6 s / d$ & $2 \cdot 8$ & $1 \cdot 7$ & 49 & 49.5 \\
\hline \multicolumn{7}{|c|}{ Block 2: Mediterranean dietary habits } \\
\hline 16. Water or infusions & Water or infusions ( 1 serving $=1$ glass $)$ & $>6 \mathrm{~s} / \mathrm{d}$ & - & - & 62 & $62 \cdot 6$ \\
\hline 17. Wine at mealtimes & White/red wine (1s = 1 glass of wine) & Yes & - & - & 8 & $8 \cdot 1$ \\
\hline 18. Limit salt in meals & & Yes & - & - & 70 & $70 \cdot 7$ \\
\hline 19. Preference for whole grains & & Yes & - & - & 50 & 50.5 \\
\hline 20. Limit snacks & $\begin{array}{l}\text { Potato chips, tortilla chips, popcorn } \\
\qquad(1 \mathrm{~s}=1 \text { bag or } 50 \mathrm{~g})\end{array}$ & $<2 \mathrm{~s} /$ week & - & - & 62 & $62 \cdot 6$ \\
\hline 21. Limit nibbling between meals & & Yes & - & - & 73 & 73.7 \\
\hline 22. Limit sugar in beverages & & Yes & - & - & 80 & $80 \cdot 8$ \\
\hline a. Consume seasonal $/$ minimally $p$ & cessed food ${ }^{c}$ & Yes & - & - & 76 & $76 \cdot 8$ \\
\hline b. Consume small portions and in & oderation ${ }^{c}$ & Yes & - & - & 71 & $71 \cdot 7$ \\
\hline \multicolumn{7}{|c|}{ Block 3: Physical activity, rest, social habits and conviviality } \\
\hline 23. Physical activity & $\begin{array}{l}\text { Jogging, walking at a fast pace, dance/ } \\
\text { aerobics, gardening, }>150 \mathrm{~min} / \text { week } \\
\text { or } 30 \mathrm{~min} / \mathrm{d}\end{array}$ & Yes & - & - & 46 & $46 \cdot 5$ \\
\hline 24. Siesta/nap & During weekends & Yes & - & - & 66 & $66 \cdot 7$ \\
\hline 25. Hours of sleep & During weekdays & $6-8 \mathrm{~h} / \mathrm{d}$ & $6 \cdot 9$ & $2 \cdot 3$ & 52 & $52 \cdot 5$ \\
\hline 26. Watching television & During weekdays & $\leq 1 \mathrm{~h} / \mathrm{d}$ & $5 \cdot 0$ & $6 \cdot 8$ & 10 & $10 \cdot 1$ \\
\hline 27. Socialising with friends & During weekends & $\geq 2 \mathrm{~h} /$ week & $2 \cdot 6$ & $3 \cdot 6$ & 46 & $46 \cdot 5$ \\
\hline 28. Collective sports & During week & $\geq 2 \mathrm{~h} /$ week & $0 \cdot 2$ & 1.0 & 3 & $3 \cdot 0$ \\
\hline c. Lunch time & During weekdays ${ }^{c}$ & $\geq 20 \mathrm{~min} / \mathrm{d}$ & $25 \cdot 1$ & $18 \cdot 8$ & 59 & 59.6 \\
\hline d. Eat in company & Family, friends, colleagues ${ }^{c}$ & Yes & - & - & 56 & $56 \cdot 6$ \\
\hline
\end{tabular}

Note. S, serves.

${ }^{a} 0$ points if criteria were not met.

${ }^{\mathrm{b}}$ Data presented as mean and standard deviation (SD), or frequency and percentage of the total group.

${ }^{c}$ Questions denoted with a letter $(\mathrm{a}, \mathrm{b}, \mathrm{c}, \mathrm{d})$ are supplementary questions of the MEDLIFE index and are not included in the final index score.

cardiometabolic markers and kidney function in people with non-dialysis dependent CKD. Key findings include moderate adherence to a Mediterranean lifestyle, employment was associated with higher adherence to a Mediterranean lifestyle, components of Mediterranean dietary habits were associated with various cardiometabolic markers and those that ate 
with others had a lower occurrence of depression. No associations between kidney function and a Mediterranean lifestyle were found.

Evidence points toward an association between adherence to a Mediterranean diet, renal function and delayed CKD progression $^{(5,30)}$. In a systematic review of nine studies, increased adherence to a Mediterranean diet was significantly associated with a $10 \%$ reduced risk of CKD in community-dwelling adults $^{(31)}$. Additionally, a cross-sectional study ( $n$ 2813) found that greater adherence to a Mediterranean diet was associated with higher eGFR in people with CKD stage $3^{(32)}$. No significant associations were observed between a Mediterranean lifestyle adherence and CKD in the present study. This may be partly explained by the small sample size and the use of different tools to measure adherence to a Mediterranean diet and/or lifestyle. The present study assessed food intake, dietary habits, physical activity and social interaction which differs from the tools used in previous studies (e.g. Mediterranean Diet Score, Mediterranean Diet Adherence Screener, Mediterranean Diet Scale, Short Mediterranean Diet Questionnaire) that predominately focused on food and/or nutrients ${ }^{(33)}$. Lifestyle factors such as physical activity and sedentary behaviour may be useful in the prevention of CKD progression as well as comorbidities such as cardiovascular disease which are common among people with $\mathrm{CKD}^{(15,18-20)}$. Therefore, the present study used an $a$ priori index tool that included some of these lifestyle factors. Despite the lack of associations between kidney function and a Mediterranean lifestyle, we did find associations between Mediterranean lifestyle components and cardiometabolic markers which may act to modulate CKD progression ${ }^{(34)}$. Nevertheless, the role of a Mediterranean lifestyle in the prevention of $\mathrm{CKD}$ and $\mathrm{CKD}$ progression requires further investigation.

Proposed strategies to attenuate CKD development and progression is to effectively manage risk factors of CKD, including underlying comorbidities like cardiovascular disease, hypertension and diabetes ${ }^{(16,34,35)}$. Our findings demonstrated that adherence to a Mediterranean lifestyle, especially Mediterranean dietary habits, was associated with favourable cardiometabolic health markers. These findings are supported by a meta-analysis of eleven studies ${ }^{(36)}$ which reported that in non-CKD populations those with the highest adherence to a Mediterranean diet had $24 \%$ lower risk of incident cardiovascular disease and $28 \%$ lower risk of incident coronary heart disease. In agreement, a recent meta-analysis of six trials showed that the Mediterranean diet had positive effects on cardiovascular parameters, including total cholesterol and blood pressure ${ }^{(12)}$. Likewise, a meta-analysis of nine randomised control trials demonstrated that a Mediterranean diet had beneficial effects on weight and cardiovascular risk factors (total cholesterol, triacylglycerols and blood pressure) in people with type 2 diabetes mellitus ${ }^{(11)}$. Furthermore, a parallel-group, intervention trial that assessed the efficacy of Mediterranean diets on primary cardiovascular prevention (PREDIMED study) among 7447 people, a Mediterranean diet supplemented with extra-virgin olive oil or nuts, was associated with a lower rate of major cardiovascular events (myocardial infarction, stroke or death from cardiovascular causes) compared with a reduced-fat $\operatorname{diet}^{(8)}$. Similarly, a cross-sectional study in Australia found that higher adherence to a Mediterranean diet was associated with lower total cholesterol and LDL-cholesterol levels, systolic blood pressure and a lower risk of dyslipidaemia ${ }^{(20)}$. Taken together, a Mediterranean diet is effective to improve cardiovascular health, potentially reducing CKD development and progression ${ }^{(16)}$. Notably, the role of dietary habits and other lifestyle factors, such as the physical lifestyle environment, was not assessed. A surprising result from the present study was the unexpected inverse association between total cholesterol and some Mediterranean dietary habits. This may be explained by the potential 6-month lag between the measurement of biochemical parameters and completion of the survey. Furthermore, perhaps individual dietary preferences did not necessarily translate into action.

Interestingly, an association between eating in company and lower presence of depression was identified in the present study. Eating in company represents social support and a sense of community; thus, conviviality of meals may positively affect dietary behaviour and, in turn, health status ${ }^{(14)}$. In fact, high adherence to a Mediterranean diet and socialisation was associated with a lower risk of developing depression in a prospective cohort study of Spanish adults ${ }^{(22)}$. The present study, therefore, supports the notion that non-nutritional aspects of a Mediterranean lifestyle, such as social and cultural factors, are fundamental to help procure the well-known benefits of a Mediterranean lifestyle.

In the present study, adherence to certain Mediterranean dietary habits was associated with improved glycaemia and a lower frequency of diagnosed type 2 diabetes mellitus. Our findings are in agreement with the body of evidence on the Mediterranean diet and glycaemia ${ }^{(11,12)}$. A meta-analysis of nine studies, investigating the effects of a Mediterranean diet on glycaemic control and cardiovascular risk factors, highlighted that adherence was associated with reduced levels of $\mathrm{HbA1c}$, fasting glucose and insulin among patients with type 2 diabetes $^{(11)}$. Similarly, a meta-analysis of six studies found that a Mediterranean diet had positive effects on plasma glucose in most healthy adults ${ }^{(12)}$. It is concluded that management of type 2 diabetes mellitus may improve with adherence to a Mediterranean diet, thereby slowing renal function decline.

Non-adherence to a Mediterranean lifestyle was observed in the present study. Adherence may be influenced by contextual factors, including the fact that participants were from a non-Mediterranean country, as well as factors relating to food access, food acceptance and socio-cultural norms ${ }^{(18,37)}$. Difficulty adhering to a Mediterranean diet within Australia, with the absence of an intensive intervention, was highlighted in a recent systematic review ${ }^{(37)}$. Potential avenues to improve adherence included the translation of key Mediterranean diet principles into the Australian Dietary Guidelines, thus acknowledging socio-cultural norms, sustainability, acceptability and palatability ${ }^{(37)}$. Nevertheless, further research is warranted into the transferability of a Mediterranean diet and lifestyle into recommendations for non-dialysis dependent 
CKD patients from non-Mediterranean countries while maintaining associated health benefits. Employment was also linked with higher adherence to a Mediterranean lifestyle in the present study. Evidence suggests improved health outcomes for older adults that maintain some form of employment status after the age of 65 years ${ }^{(37,38)}$. With this in mind, the role of employment in achieving and maintaining a healthier lifestyle in older adults with non-dialysis dependent CKD needs further investigation.

The limitations of the present study include a small sample size, a single centre study and the use of self-reported tools which can result in reporting errors or bias ${ }^{(39-41)}$. Furthermore, there was potential for up to a 6-month variance between measured biochemical parameters and data collection within the research study. Due to financial constraints, fasting blood samples could not be taken at the time of the study but were sourced from medical records. Retirement was not recorded, and it was, therefore, not possible to distinguish between unemployment due to retirement or due to inability to secure work. As the majority of participants $(71.7 \%)$ were 65 -years and older, it is possible that many were retired; however, it cannot be assumed. In addition, the crosssectional nature of the study design precludes conclusions pertaining to causality between a Mediterranean lifestyle, kidney function and cardiometabolic markers ${ }^{(42)}$.

\section{Conclusion}

In summary, despite only moderate adherence to a Mediterranean lifestyle, components of a Mediterranean lifestyle were associated with improved health outcomes in this group of people with non-dialysis dependent CKD. The present study extends the body of knowledge by highlighting the potential role of Mediterranean lifestyle factors such as dietary habits, the physical environment and social interaction on cardiometabolic markers, kidney function and/or other health outcomes in people with non-dialysis dependent CKD. Further studies are warranted in larger samples investigating the role of both dietary and non-dietary Mediterranean lifestyle factors in the progression of CKD, as well as factors influencing adherence. In addition, validated tools measuring Mediterranean lifestyle quality, contextualised for people from non-Mediterranean countries, are needed.

\section{Acknowledgements}

The authors thank the staff and participants of the Sunshine Coast Hospital and Health Service Renal Outpatient Unit for their significant contribution to this study. The assistance provided by Dr. Benjamin Law for data collection is greatly appreciated. This study was funded by the School of Health and Sport Sciences, University of the Sunshine Coast. In-kind contribution was received from the University of the Sunshine Coast and Sunshine Coast Hospital and Health Service.

This research received no specific grant from any funding agency, commercial or not-for-profit sectors.

H. W., L. S. and N. G. identified the research question and study design; K. B. contributed to the study design, formulation of research questions, recruitment, data collection, data analysis and interpretation and wrote the first manuscript draft; H. W. contributed to research questions, data analysis, interpretation and writing of final manuscript; N. G. contributed to research questions, study design and recruitment; All authors read and approved the final version of the manuscript.

The authors declare that they have no relevant financial or personal conflicts of interest.

\section{References}

1. Hill NR, Fatoba ST, Oke JL, et al. (2016) Global prevalence of chronic kidney disease - a systematic review and meta-analysis. PLOS ONE 11, e0158765.

2. Webster AC, Nagler EV, Morton RL, et al. (2017) Chronic kidney disease. Lancet 389, 1238-1252.

3. Lopez-Vargas PA, Tong A, Sureshkumar P, et al. (2013) Prevention, detection and management of early chronic kidney disease: a systematic review of clinical practice guidelines. Nephrology (Carlton) 18, 592-604.

4. Slattery ML (2008) Defining dietary consumption: is the sum greater than its parts? Am J Clin Nutr 88, 14-15.

5. Campbell KL \& Carrero JJ (2016) Diet for the management of patients with chronic kidney disease: it is not the quantity, but the quality that matters. J Ren Nutr 26, 279-281.

6. Chauveau P, Aparicio M, Bellizzi V, et al. (2018) Mediterranean diet as the diet of choice for patients with chronic kidney disease. Nephrol Dial Transplant 33, 725-735.

7. Asghari G, Farhadnejad H, Mirmiran P, et al. (2017) Adherence to the Mediterranean diet is associated with reduced risk of incident chronic kidney diseases among Tehranian adults. Hypertens Res 40, 96-102.

8. Estruch R, Ros E, Salas-Salvadó J, et al. (2018) Primary prevention of cardiovascular disease with a Mediterranean diet supplemented with extra-virgin olive oil or nuts. N Engl J Med 378, e34.

9. Simopoulos AP (2001) The Mediterranean diets: what is so special about the diet of Greece? The scientific evidence. J Nutr 131, 3065S-3073S.

10. Palmer SC, Maggo JK, Campbell KL, et al. (2017) Dietary interventions for adults with chronic kidney disease. Cochrane Database Syst Rev 4, CD011998.

11. Huo R, Du T, Xu Y, et al. (2015) Effects of Mediterranean-style diet on glycemic control, weight loss and cardiovascular risk factors among type 2 diabetes individuals: a meta-analysis. Eur J Clin Nutr 69, 1200-1208.

12. Nordmann AJ, Suter-Zimmermann K, Bucher HC, et al. (2011) Meta-analysis comparing Mediterranean to low-fat diets for modification of cardiovascular risk factors. Am J Med 124, 841-851.e842.

13. Hu EA, Coresh J, Anderson CAM, et al. (2020) Adherence to healthy dietary patterns and risk of CKD progression and all-cause mortality: findings from the CRIC (Chronic Renal Insufficiency Cohort) Study. Am J Kidney Dis 7, 235-244.

14. Bach-Faig A, Berry EM, Lairon D, et al. (2011) Mediterranean diet pyramid today. Science and cultural updates. Public Health Nutr 14, 2274-2284.

15. MacKinnon HJ, Wilkinson TJ, Clarke AL, et al. (2018) The association of physical function and physical activity with all-cause mortality and adverse clinical outcomes in nondialysis chronic kidney disease: a systematic review. Ther Adv Chronic Dis 9, 209-226.

16. Ricardo AC, Anderson CA, Yang W, et al. (2015) Healthy lifestyle and risk of kidney disease progression, atherosclerotic events, and death in CKD: findings from the Chronic Renal Insufficiency Cohort (CRIC) Study. Am J Kidney Dis 65, 412-424.

17. Georgousopoulou EN, Mellor DD, Naumovski N, et al. (2017) Mediterranean lifestyle and cardiovascular disease prevention. Cardiovasc Diagn Ther 7, S39-S47.

18. Afsar B, Siriopol D, Aslan G, et al. (2018) The impact of exercise on physical function, cardiovascular outcomes and quality of life in 
chronic kidney disease patients: a systematic review. International Urology and Nephrology 50, 885-904.

19. Lynch BM, White SL, Owen N, et al. (2010) Television viewing time and risk of chronic kidney disease in adults: the AusDiab Study. Ann Behav Med 40, 265-274.

20. Aridi YS, Walker JL, Roura E,et al. (2020) Adherence to the Mediterranean diet and chronic disease in Australia: national nutrition and physical activity survey analysis. Nutrients 12, 1-15.

21. Patnode CD, Evans CV, Senger CA et al. (2017) U.S. Preventive Services Task Force evidence syntheses, formerly systematic evidence reviews. In Behavioral Counseling to Promote a Healthful Diet and Physical Activity for Cardiovascular Disease Prevention in Adults Without Known Cardiovascular Disease Risk Factors: Updated Systematic Review for the US Preventive Services Task Force. Rockville (MD): Agency for Healthcare Research and Quality (US).

22. Sánchez-Villegas A, Ruíz-Canela M, Gea A, et al. (2016) The association between the Mediterranean lifestyle and depression. Clin Psychol Sci 4, 1085-1093.

23. Diolintzi A, Panagiotakos DB \& Sidossis LS (2019) From Mediterranean diet to Mediterranean lifestyle: a narrative review. Public Health Nutr 22, 2703-2713.

24. Stevens PE \& Levin A (2013) Evaluation and management of chronic kidney disease: synopsis of the kidney disease: improving global outcomes 2012 clinical practice guideline. Ann Intern Med 158, 825-830.

25. O’Brien E, Asmar R, Beilin L, et al. (2005) Practice guidelines of the European Society of Hypertension for clinic, ambulatory and self blood pressure measurement. J Hypertens 23, 697-701.

26. Stewart A M-JM, Olds T, et al. (2011) International Standards for Anthropometric Assessment. Potchefstroom: International Society for the Advancement of Kinanthropometry.

27. WHO (1995) Physical status: the use and interpretation of anthropometry. Report of a WHO Expert Committee. World Health Organ Tech Rep Ser 854, 1-452.

28. Sotos-Prieto M, Moreno-Franco B, Ordovas JM, et al. (2015) Design and development of an instrument to measure overall lifestyle habits for epidemiological research: the Mediterranean lifestyle (MEDLIFE) index. Public Health Nutr 18, 959-967.

29. Faul F, Erdfelder E, Buchner A, et al. (2009) Statistical power analyses using $G^{*}$ Power 3.1: tests for correlation and regression analyses. Behav Res Methods 41, 1149-1160.
30. Banerjee T, Liu Y \& Crews DC (2016) Dietary patterns and CKD progression. Blood Purif 41, 117-122.

31. Hansrivijit P, Oli S, Khanal R, et al. (2020) Mediterranean diet and the risk of chronic kidney disease: a systematic review and meta-analysis. Nephrology (Carlton) 25, 913-918.

32. Heindel J, Baid-Agrawal S, Rebholz CM, et al. (2020) Association between dietary patterns and kidney function in patients with chronic kidney disease: a cross-sectional analysis of the German Chronic Kidney Disease Study. J Ren Nutr 30, 296-304.

33. Gil A, Martinez de Victoria E \& Olza J (2015) Indicators for the evaluation of diet quality. Nutr Hosp 31, Suppl. 3, 128-144.

34. Lee W-C, Lee Y-T, Li L-C, et al. (2018) The number of comorbidities predicts renal outcomes in patients with stage 3-5 chronic kidney disease. J Clin Med 7.

35. Fraser SD, Roderick PJ, May CR, et al. (2015) The burden of comorbidity in people with chronic kidney disease stage 3: a cohort study. BMC Nephrol 16, 193.

36. Grosso G, Marventano S, Yang J, et al. (2017) A comprehensive meta-analysis on evidence of Mediterranean diet and cardiovascular disease: are individual components equal? Crit Rev Food Sci Nutr 57, 3218-3232.

37. Minami U, Nishi M, Fukaya T, et al. (2015) Effects of the change in working status on the health of older people in Japan. PLOS ONE 10, e0144069.

38. Staudinger UM, Finkelstein R, Calvo E, et al. (2016) A global view on the effects of work on health in later life. The Gerontologist 56, S281-S292.

39. Kipnis V, Subar AF, Midthune D, et al. (2003) Structure of dietary measurement error: results of the OPEN biomarker study. Am J Epidemiol 158, 14-21, discussion 22-16.

40. Shim JS, Oh K \& Kim HC (2014) Dietary assessment methods in epidemiologic studies. Epidemiol Health 36, e2014009.

41. Halbesma N, Bakker SJ, Jansen DF, et al. (2009) High protein intake associates with cardiovascular events but not with loss of renal function. J Am Soc Nephrol 20, 1797-1804.

42. Boushey C, Harris J, Bruemmer B, et al. (2006) Publishing nutrition research: a review of study design, statistical analyses, and other key elements of manuscript preparation, part 1. J Am Diet Assoc 106, 89-96. 